\title{
VGF peptides as novel biomarkers in Parkinson's disease
}

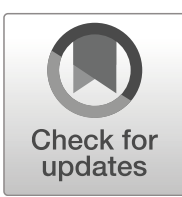

\author{
Cristina Cocco ${ }^{1}$ (1) - Giulia Corda ${ }^{1}$ - Carlo Lisci ${ }^{1}$ Barbara Noli ${ }^{1} \cdot$ Manolo Carta ${ }^{1}$. Carla Brancia ${ }^{1}$ Elias Manca ${ }^{1}$. \\ Carla Masala ${ }^{1}$. Francesco Marrosu ${ }^{2} \cdot$ Paolo Solla $^{2} \cdot$ Barbara Manconi $^{3} \cdot$ Paolo Bongioanni ${ }^{4}$. Gian-Luca Ferri ${ }^{1}$
}

Received: 7 May 2019 / Accepted: 23 October 2019

(C) Springer-Verlag GmbH Germany, part of Springer Nature 2019

\begin{abstract}
Parkinson's disease (PD) is characterized by a progressive degeneration of dopaminergic neurons in the substantia nigra (SN). At disease onset, a diagnosis is often difficult. VGF peptides are abundant in the SN and peripheral circulation; hence, we investigate whether their plasma profile may reflect the brain dopamine reduction. Using antibodies against the VGF C-terminal portion, we analyzed the rat brain and human plasma, with immunohistochemistry and ELISA. Rats were unilaterally lesioned with 6hyroxydopamine and sacrificed either 3 or 6 weeks later with or without levodopa treatment. Plasma samples were obtained from PD patients, either at the time of diagnosis (group 1, drug naïve, $n=23$ ) or upon dopamine replacement (group 2, 1-6 years, $n=24$; group 3, > 6 years, $n=16$ ), compared with age-matched control subjects (group $4, n=21$ ). Assessment of the olfactory function was carried out in group 2 using the "Sniffin' Sticks" test. VGF immunoreactivity was present in GABAergic neurons and, on the lesioned side, it was reduced at 3 weeks and abolished at 6 weeks after lesion. Conversely, upon levopoda, VGF labeling was restored. In PD patients, VGF levels were reduced at the time of diagnosis (1504 $\pm 587 \mathrm{vs} .643 \pm 348 \mathrm{pmol} / \mathrm{mL}$, means \pm S.E.M: control vs. naïve; $p<0.05)$ but were comparable with the controls after long-term drug treatment $(>6$ years). A linear correlation was demonstrated between VGF immunoreactivity and disease duration, levodopa equivalent dose and olfactory dysfunction. Plasma VGF levels may represent a useful biomarker, especially in the early stages of PD.
\end{abstract}

Keywords Parkinson's disease $\cdot$ Biomarker $\cdot$ Plasma $\cdot$ VGF peptides $\cdot$ Substantia nigra $\cdot$ Dopamine $\cdot$ Substance $P$

\section{Introduction}

Parkinson's disease (PD) is a neurodegenerative disorder characterized by a progressive loss of dopaminergic neurons in the substantia nigra (SN). Unfortunately, there is no precise diagnosis at the time of disease onset. Although non-motor symptoms, such as olfactory dysfunction

C.C and G.C contributed equally to this paper.

Cristina Cocco

cristina.cocco@unica.it

1 Department of Biomedical Sciences, NEF-Laboratory, University of Cagliari, 09042, Monserrato, Cagliari, Italy

2 Department of Neurology, "Azienda Universitario Ospedaliera" of Cagliari and University of Cagliari, Cagliari, Italy

3 Department of Life and Environmental Sciences, University of Cagliari, Cagliari, Italy

4 Department of Neuroscience, Neurorehabilitation Unit, University of Pisa, Pisa, Italy
(Masala et al. 2018), or REM sleep behavior disorder (Postuma et al. 2015) may appear several years before motor symptoms in PD patients, they do not seem to adequately support an early PD diagnosis. Thus, further novel diagnostic tools, including biochemical measurements in body fluids, are under consideration to improve early diagnosis. Potential candidates as biomarkers include molecules that can show alterations related to changes in brain dopamine levels and, at the same time, be detectable in blood, which is an easy obtainable biological fluid. VGF peptides are members of a family of structurally diverse peptides, all derived from the $v g f$ (non-acronymic) gene that encodes one precursor of about $90 \mathrm{kDa}$ whose transcription and secretion are induced through neurotrophins (Ferri et al. 2011). The VGF precursor is composed of 617,615 aa in rat/mouse and human respectively, with minor sequence differences ( $>85 \%$ identity, rat to human). Of several VGF peptides identified, those derived from the Cterminal portion of the precursor (VGF C-t peptides) are most abundant in human plasma (Brancia et al. 2016; D'Amato et al. 2015) as well as richly represented in the 
Table 1 Patient's features

\begin{tabular}{|c|c|c|c|c|c|c|c|}
\hline P \# & $\begin{array}{l}\text { Years of disease } \\
\text { since diagnosis }\end{array}$ & $\begin{array}{l}\text { Hoehn \& } \\
\text { Yahr scores }\end{array}$ & $\begin{array}{l}\text { Total levodopa } \\
\text { equivalent dose (mg/day) }\end{array}$ & P \# & $\begin{array}{l}\text { Years of disease } \\
\text { since diagnosis }\end{array}$ & $\begin{array}{l}\text { Hoehn \& } \\
\text { Yahr scores }\end{array}$ & $\begin{array}{l}\text { Total levodopa } \\
\text { equivalent dose (mg/day) }\end{array}$ \\
\hline 1 & 6 & 3 & 811.1 & 47 & 0 & 1 & - \\
\hline 2 & 15 & 4 & 775.9 & 48 & 0 & 2 & - \\
\hline 3 & 3 & 3 & 350 & 49 & 0 & 2 & - \\
\hline 4 & 3 & 1.5 & 425.1 & 50 & 0 & 1.5 & - \\
\hline 5 & 13 & 3 & 1171.5 & 51 & 0 & 1.5 & - \\
\hline 6 & 4 & 2 & 281.8 & 52 & 0 & 3 & - \\
\hline 7 & 10 & 2.5 & 910.7 & 53 & 0 & 2 & - \\
\hline 8 & 6 & 2 & 600 & 54 & 0 & 2 & - \\
\hline 9 & 13 & 2.5 & 550.3 & 55 & 0 & 1 & - \\
\hline 10 & 7 & 2.5 & 975.9 & 56 & 0 & 1.5 & - \\
\hline 11 & 4 & 2 & 262 & 57 & 0 & 1 & - \\
\hline 12 & 6 & 3 & 400 & 58 & 0 & 1 & - \\
\hline 13 & 15 & 2.5 & 925.5 & 59 & 0 & 1.5 & - \\
\hline 14 & 2 & 3 & 2000 & 60 & 0 & 1.5 & - \\
\hline 14 & 2 & 3 & 157 & 61 & 0 & 2 & - \\
\hline 15 & 7 & 2 & 660 & 62 & 0 & 1 & - \\
\hline 16 & 24 & 2.5 & 550.3 & 63 & 0 & 2 & - \\
\hline
\end{tabular}

Table 1 (continued) brain (Trani et al. 2002). Such peptides are specifically expressed and localized in neurons of the $\mathrm{SN}$ as well as within many other areas including the cortex, hippocampus and hypothalamus (Van Den Pol et al. 1994). In spite of the expression of VGF C-t peptides in certain endocrine organs such as pancreas, pituitary, ovary and stomach (Cocco et al. 2007; Noli et al. 2014; Noli et al. 2015; Brancia et al. 2010), changes in peripheral blood are so far either related to certain stimuli (such as acute glucose load) (D'Amato et al. 2015) or reported in a specific rat estrous phase (Noli et al. 2014). In human blood, levels are modulated after glucose load in healthy subjects (D'Amato et al. 2015) and downregulated in the later phase of amyotrophic lateral sclerosis (ALS) (Brancia et al. 2016). VGF fragments containing the $\mathrm{C}$ terminus portion remain to be identified in cerebro-spinal fluid (CSF), despite the presence of other VGF fragments (not containing the C terminus portion) being reported (Ferri et al. 2011). Biological activity has so far addressed mainly two VGF C-t peptides, namely AQEE-30 and TLQP-62, which acutely increase the synaptic charge in the hippocampal neurons, in a dose-dependent manner, whereas the N-terminal peptides have no effect (Alder et al. 2003). Using post-mortem parietal brain cortex from $\mathrm{PD}$ patients we previously reported a reduction in two VGF peptides, namely TPGH and NERP-1, while the VGF C-t peptides were expressed but unchanged (Cocco et al. 2010). Interestingly, using RNA sequencing to assess gene expression in the cortex (posterior cingulate), it has been reported that PD patients reveal a VGF gene downregulation, compared with controls 
(Smith et al. 2016). To address a role of the VGF C-t peptides as early PD biomarkers, we studied possible changes of these peptides by analyzing brain of the unilaterally 6hyroxydopamine (6OHDA)-lesioned rat model of PD in parallel with blood samples of PD patients, both at different levels of dopamine system degeneration. VGF C-t peptide changes have been investigated using antibodies that we previously produced against the proVGF C-t portion of either rat or human, for immunohistochemistry (IHC) and enzyme-linked immunosorbent assay (ELISA) analyses.

\section{Materials and methods}

\section{Animal care and use}

Sprague-Dawley male rats (Charles River, Lecco, Italy: 14-15 weeks, 300-350 g body weight, 4/cage) were housed under standard conditions: $23 \pm 2{ }^{\circ} \mathrm{C}, 60 \pm 10 \%$ relative humidity, 12-12-h light-dark cycle, with ad libitum access to food until the experiments. Rats were subdivided into the following groups: unlesioned (group 1, $n=8$ ), lesioned and sacrificed either at 3 weeks (group 2, $n=7$ ) or at 6 weeks (group 3, $n=7$ ) as well as treated with L-3,4-dihydroxyphenylalanine (LDopa: $6 \mathrm{mg} / \mathrm{kg}$ plus $6 \mathrm{mg} / \mathrm{kg}$ benserazide, i.p., daily for 1 week) after 6 weeks post-lesion and then sacrificed (group 4, $n=6$ ). Rat surgeries started at 10 am and rats were deeply anesthetized (under gas anesthesia induced by isofluran, IsoFlo, 3\% isoflurane vaporized in $\mathrm{O} 2 / \mathrm{N} 2 \mathrm{O} 50: 50$ Italy) and treated with injections of 6OHDA $(12 \mu \mathrm{g} / 4 \mu \mathrm{L}$ of saline containing $0.1 \%$ ascorbic acid in $0.9 \%$ saline) via a Hamilton syringe into the left medial forebrain bundle (anteroposterior $=-4.4$; lateral $=+1.2 ;$ ventrodorsal $=-7.8$; at a rate of 1.0 $\mu \mathrm{L} / \mathrm{min}$ ). After surgery, to avoid suffering, animals were disposed in a warm blanket and constantly monitored. For IHC, rats were sacrificed by perfusion with $4 \%$ paraformaldehyde (in phosphate-buffered saline (PBS) $0.01 \mathrm{~mol} / \mathrm{L}$ PO4, 0.15 $\mathrm{mol} / \mathrm{L} \mathrm{NaCl}$ ) injected through the left ventricle. The brains were collected and stored in PBS containing $70 \mathrm{~g} / \mathrm{L}$ sucrose. Unlesioned rats used for ELISA (group $1, n=4$ ) and HPLC high-resolution-ESI-MS/MS/MS (pooled samples, $n=4$ ) were sacrificed, under gas anesthesia with isofluran (see above), by decapitation to remove the brains from the skulls. For ELISA, slice samples (coronal sections of $2 \mathrm{~mm}$ ) were obtained using a cooled matrix. The different brain areas (frontal cortex, SN and caudate nucleus) were dissected from the brain slices using punches of 3-, 4- and 5-mm dimensions as appropriate, following the coordinates of the Paxinos Atlas of the rat brain. For both ELISA and HPLC analyses, samples were extracted in PBS containing protease inhibitor cocktail (PIC: P8340, Sigma-Aldrich, Schnelldorf, Germany; 10 mL/g tissue), homogenized using an Ultra-Turrax Homogenizer (Ika-Werke, Staufen, Germany, $3 \mathrm{~min}$ ), heated in a boiling water bath (10-15 min), centrifuged (3000 rpm, 10-15 min) and frozen until use.

\section{Human assessment}

This study involves male patients with PD ( $n=63$, age mean 71.7 and 67.9 for patients and controls, respectively), either at the time of diagnosis (group 1, drug naïve, $n=23$ ), or upon dopamine replacement therapy (group 2, 1-6 years treatment, $n=24$; group $3,>6$ years treatment, $n=16$ ), compared with age-matched control subjects, without any neurological or neurodegenerative diseases (group 4, $n=21$ ), all recruited between 1999-2016 at the Neurorehabilitation Unit, of the Neuroscience Department, University of Pisa and at the Department of Neurology, Azienda UniversitariaOspedaliera of Cagliari at the University of Cagliari. Blood samples taken from fasted patients (in the morning between 9 $11 \mathrm{am}$ ) were positioned into tubes containing ethylenediamine tetraacetic acid (EDTA $1.78 \mathrm{mg} / \mathrm{mL})$, centrifuged $(3000 \times \mathrm{g}, 10$ $\mathrm{min}$ ) to obtain plasma and frozen until use. Male patients were involved in view of the inability to provide an appropriate

\section{a}

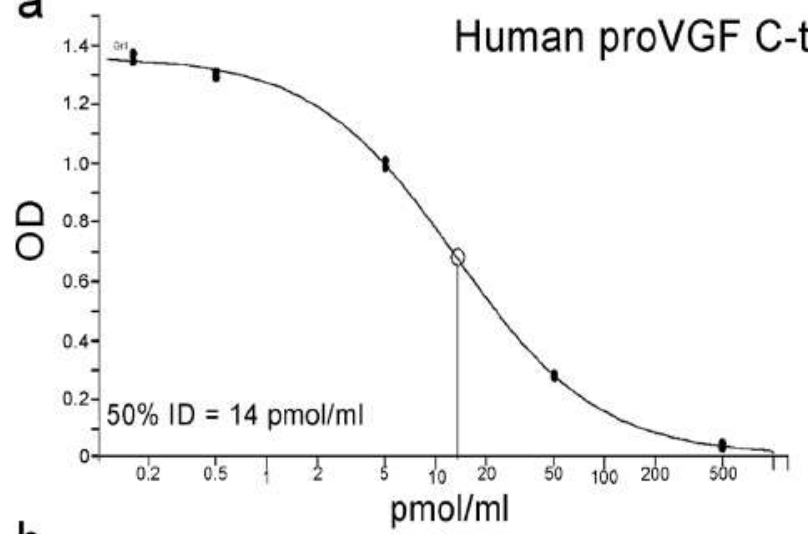

$b$

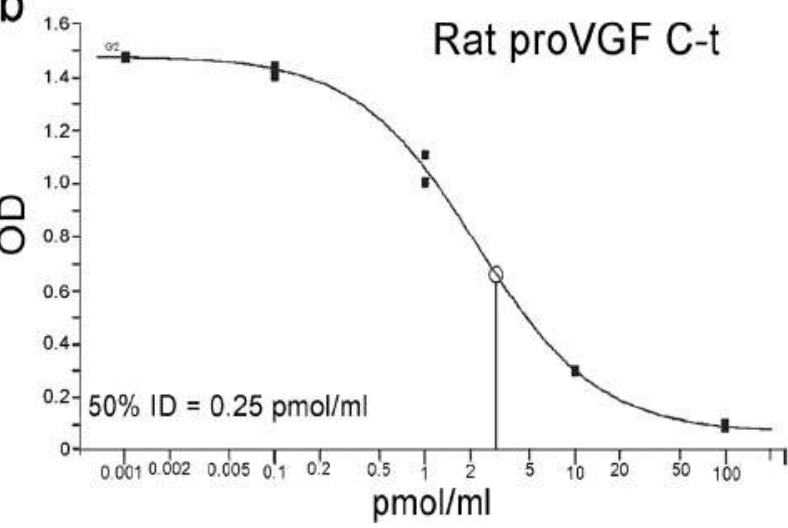

Fig. 1 VGF C-t curves. The standard curves were obtained using a range of concentrations of the "reference" peptides in solution (rat IEHVLLHRP and human IEHVLLRRP) and a fixed amount of the same peptides onto the well, competing for the rat/humanVGF C-t antibody. ID, inhibitory dose; $\mathrm{pmol} / \mathrm{mL}$, picomoles/milliliters 


\section{Author's personal copy}

Cell Tissue Res

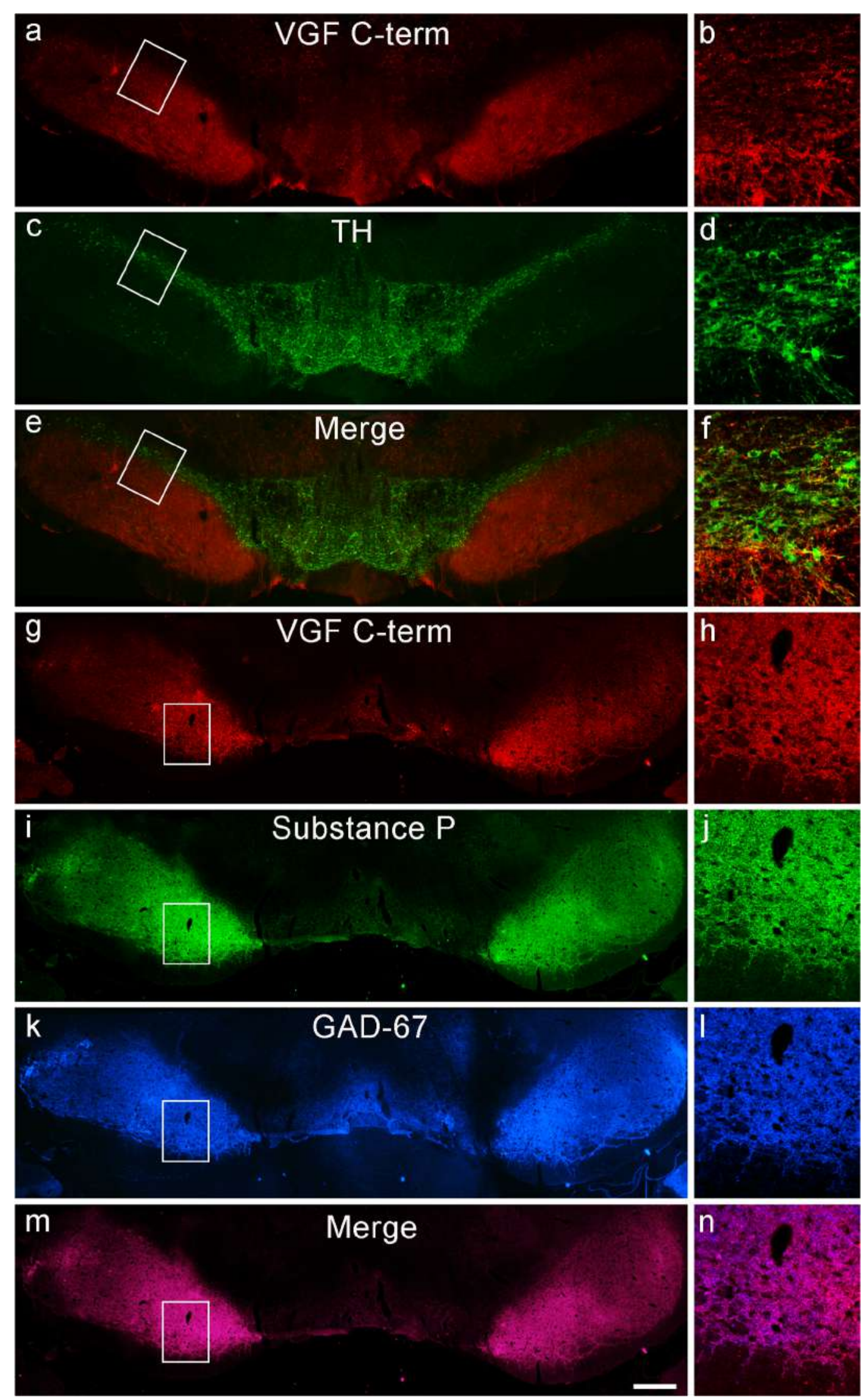


4 Fig. 2 Phenotype of VGF C-t positive neurons. In the SN, double staining using antibodies against VGF C-t peptides (a, b Cy3, red labeling) and $\mathrm{TH}$ (c, $\mathbf{d} \mathrm{Cy} 2$, green labeling) shows that there is not co-localization profile, as revealed by the merge panel $(\mathbf{e}, \mathbf{f})$. Instead, the VGF immunostaining profile (g, h Cy3, red labeling) is similar to that obtained using antibodies against substance $\mathrm{P}(\mathbf{i}, \mathbf{j}$ Cy2, green labeling) and GAD-67 (k, AMCA, blue labeling), according to the high percentage of colocalization revealed by triple staining ( $\mathbf{m}, \mathbf{n}$ merge panels). Scale bars 50 and $10 \mu \mathrm{m}$, low and high amplification, respectively

female number to identify possible gender differences. The diagnosis of PD was defined according to the United Kingdom Brain Bank criteria and drawn by one neurologist specialized in movement disorders with stable medication use. Patients with atypical parkinsonisms such as multiple system atrophy, progressive supranuclear palsy, or corticobasal degeneration, as well as patients with secondary forms such as vascular and drug-induced parkinsonism were not included in this study. Patients were subjected to complete examination, including disease duration (time passed since diagnosis), pharmacological treatments and measures of disease severity assessed by scores of the Hoehn and Yahr (HY) scale (Hoehn and Yahr 1967), rated during an "off" phase (12 h off drugs). The not-naïve patients were largely under L-Dopa, only 6 were treated solely with dopamine agonists. Among the PD population, 19\% showed dyskinesia, while less than $30 \%$ had cognitive impairment. Mean HY scores, years of PD duration from first motor symptom onset and L-Dopa equivalent daily dose (LEDD) are reported in Table 1 . In addition, a subgroup of short-term treated patients $(n=9)$ underwent the olfactory test.

\section{Evaluation of the olfactory function}

Olfactory function in patients was evaluated using the Sniffin' Sticks test (Burghart Messtechnik, Wedel, Germany) (Masala et al. 2018). Felt-tip pens filled with odors were used to deliver the olfactory stimuli. During the odor presentation, the cap was removed by the experimenter for approximately $3 \mathrm{~s}$ and the pen's tip was placed approximately $2 \mathrm{~cm}$ in front of both nostrils. Three different olfactory functions were assessed for each patient. First, the odor threshold (OT) was determined for n-butanol with 16 stepwise dilutions. The threshold was evaluated using the single-staircase technique based on a threealternative forced-choice task (3AFC). The score ranged from 16 (participants who were able to detect the lowest concentration of n-butanol) to 1 (participants who were unable to detect the highest concentration). Second, the odor discrimination (OD) was assessed over 16 trials. In the discrimination test, three pens were presented, two containing the same odor and the third containing the target odorant (3AFC task). The discrimination score represented the sum of the correct responses and ranged from 0 to 16 . Odor identification (OI) was assessed by using a series of 16 pen sticks. Participants had to identify the odor from a list of four options from which they had to choose the correct answer. The interval between each test was 20-30 s. The total odor identification score for each participant corresponded to the number of correct responses and ranged from 0 to 16. A total score (thresholddiscrimination-identification (TDI)) was calculated for each participant: a score as $\geq 30.5, \leq 30.5$ and $\leq 16.5$ indicated normosmia, hyposmia and functional anosmia, respectively.

\section{VGF C-t antiserum}

For immunizations, the antigens were conjugated with bovine thyroglobulin via an additional D-tyrosine. At the C-terminal end of the human and rat proVGF, the Arg613-Arg614Pro615 and His615-Arg616-Pro617 sequences, respectively, are found. Hence, the $\mathrm{C}$ terminus antisera were raised against the corresponding nonapeptides. Western blot was previously carried out using rat brain extracts and a subset of bands were detected, including the $90 \mathrm{kDa}$ polypeptide, compatible with the VGF precursor, as well as lower molecular mass peptides (Trani et al. 1995). Molecular characterization of the antibody with human tissues was done by gel chromatography coupled to ELISA using brain cortex (Cocco et al. 2010) plasma and fibroblasts (Brancia et al. 2016).

\section{Immunohistochemistry}

After fixation time, brains were included in an embedding medium and cut (at $10 \mu \mathrm{m}$ ) using a HM-560 cryomicrotome (Microm; Walldorf, Germany). Double and triple immunofluorescence experiments were carried out mixing the rabbit anti VGF C-t antibody, (1:5000), with the sheep anti-tyrosine hydroxylase (TH; 1:600; AB_373131), mouse anti-glutamic acid decarboxylase (GAD-67; 1:2000: AB_966813), and/or guinea pig anti-substance $\mathrm{P}(\mathrm{AB}$ 3 380299, 1:400) all diluted in PBS containing $30 \mathrm{~mL} / \mathrm{L}$ of normal donkey serum, $30 \mathrm{~mL} /$ $\mathrm{L}$ of normal rat serum and $0.02 \mathrm{~g} / \mathrm{L} \mathrm{NaN}_{3}$. Sections were then incubated overnight in a humid chamber with the primary antibodies, while the relevant species-specific donkey secondary antibody/ies, conjugated with either $\mathrm{Cy}_{3}, \mathrm{Cy}_{2}$, or AMCA (anti-guinea pig: AB_2340460 or AB_2340467; anti-mouse: AB_2341099 or AB_2340807; anti-rabbit: AB_2307443; anti-sheep: $A B \_2340735$ ) were used to reveal immunoreactivity

Table 2 VGF C-t peptide concentration in brain

\begin{tabular}{lccc}
\hline Brain area & Mean & Standard Deviation & Standard Error \\
\hline Frontal cortex & 28 & 35 & 13 \\
Substantia Nigra & 65 & 39 & 14 \\
Caudate nucleus & 8.5 & 9.5 & 3.6 \\
\hline
\end{tabular}


of the primary antibodies. Slides were covered with PBSglycerol (40\%), observed and photographed using BX41 and BX51 fluorescence microscopes (Olympus, Milan, Italy) equipped with the FujiS3 Pro digital cameras (Fujifilm, Milan, Italy). Observation of the labeling was done by a blinded operator who did not know the origin of the tissue. Routine controls included substitution of each antibody, in turn, with PBS, the use of pre-immune or non-immune sera and the testing of each secondary antibody with their respective non-relevant primary antibodies. For absorption experiments, the VGF C-t antibody was pre-incubated overnight with the nonapeptide used for immunizations (IEHVLLHRP) in a range of concentrations (0.01-100 $\mathrm{mol} / \mathrm{L}$, at $\left.4{ }^{\circ} \mathrm{C}\right)$; hence, it was used for the primary incubation on sections containing SN from control rats. The highest concentrations of homologous antigen resulted in virtually complete prevention of labeling. In order to obtain a semiquantitative determination of the immunofluorescent signal, the FIJI image processing package, based on ImageJ (NIH), was used. Briefly, at least 3 animals per group were selected and at least 3 sections (encompassing the initial, medial and final portion of the SN) per animal were immunostained with primary antibodies (anti: TH, VGF and substance P). For each section, images were acquired at standard conditions of exposition with a S3 Pro digital camera (magnification $\times 4$ ) in order to cover the entire $\mathrm{SN}$, including pars compacta and reticulata. The RGB TIFF images were first converted to 8-bit grayscale, then the boundaries of $\mathrm{SN}$ were manually traced by the user and, finally, the background fluorescent signal was removed by a manual thresholding process. The means \pm SEM of density values for TH, VGF and substance $\mathrm{P}$ were then calculated for each animal group and used for statistical analysis.

\section{ELISA}

Competitive ELISA was performed through the same VGF assay previously used for human (Brancia et al. 2016; D'Amato et al. 2015) and rat (Noli et al. 2017; D'Amato et al. 2012). Calibration curves are shown in Fig. 1. Multiwell plates (Nunc, Milan, Italy) were coated with the human or rat synthetic peptide and treated with PBS (containing $9 \%$ normal serum from the secondary antibody donor species, $20 \mathrm{nM}$ aprotinin and $1 \mathrm{mg} / \mathrm{mL}$ EDTA) for $2 \mathrm{~h}$. Primary incubations, with human/rat VGF C-t antibody, were carried out in duplicate, including serial standard dilutions in parallel with samples of human plasma or rat brain. Biotinylated secondary antibodies (Jackson, West Grove, PA, USA), streptavidin-peroxidase conjugate (Biospa, Milan, Italy) and tetrametylbenzidine (TMB X-traKem-EnTec, Taastrup, Denmank) as a substrate were used to reveal the positive labeling. Hence, the reaction was stopped with HCL $(1 \mathrm{~mol} / \mathrm{L})$ and the optical density was measured at $450 \mathrm{~nm}$ using a multilabel plate reader (Chameleon: Hidex, Turku, Finland). Recovery of synthetic peptide/s added to plasma at extraction was $>85 \%$.

\section{HPLC high-resolution-ESI-MS and MS/MS analyses}

After centrifugation (see animal section), the clear supernatant was lyophilized, redissolved in $0.5 \mathrm{~mL}$ of $0.1 \%$ trifluoroacetic acid (TFA) and analyzed by an Ultimate 3000 RSLC nano coupled with an Orbitrap Elite mass spectrometer (ThermoFisher, San Jose, CA). Separation experiments were performed using an EASY-Spray Column PepMap® RSLC C18 (3- $\mu \mathrm{m}$ particle diameter; column dimension $75 \mu \mathrm{m}$ ID $\times$ $15 \mathrm{~cm}$ ) with the following eluents: (A) $0.1 \%(\mathrm{v} / \mathrm{v})$ aqueous formic acid and (B) acetonitrile with $0.1 \%(\mathrm{v} / \mathrm{v})$ aqueous
Fig. 3 Spectrometry in rat brain. Mass spectrometry. MS/MS spectrum of the ion $[\mathrm{M}+4 \mathrm{H}] 4+$ $538.02 \mathrm{~m} / \mathrm{z}$ of VGF (Exp. Monoisotopic [MH]+: 2148.076 $\pm 0.04)$ is manually annotated and in agreement with the sequence EQEELENYIEHVLLHRP of the VGF601-617

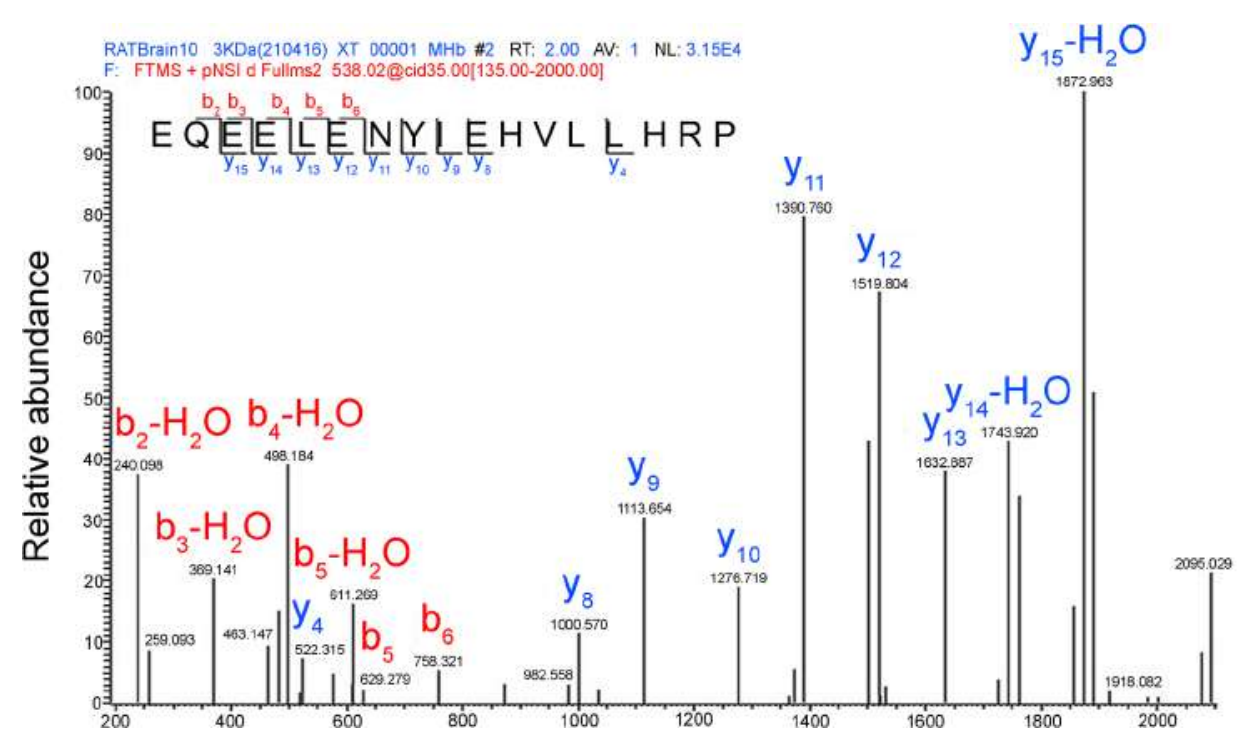


$\mathrm{TH}$

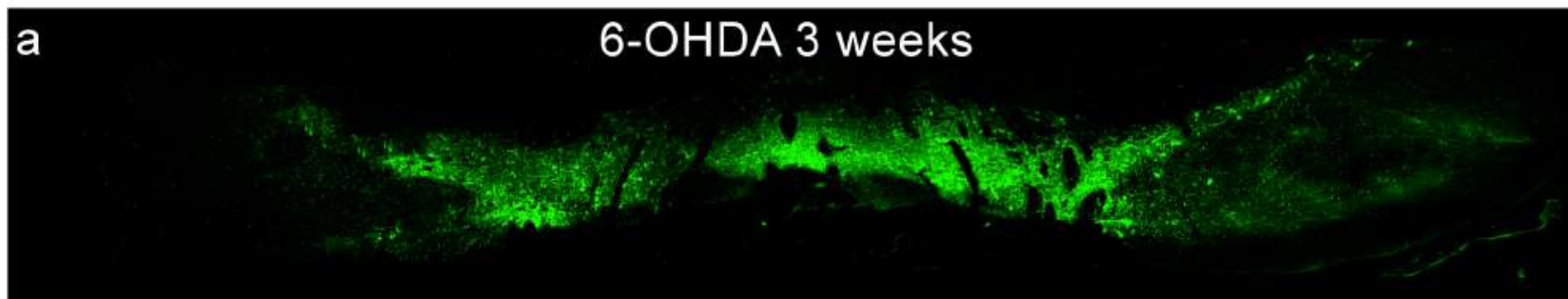

$\mathrm{b}$

\section{6-OHDA 3 weeks threshold}
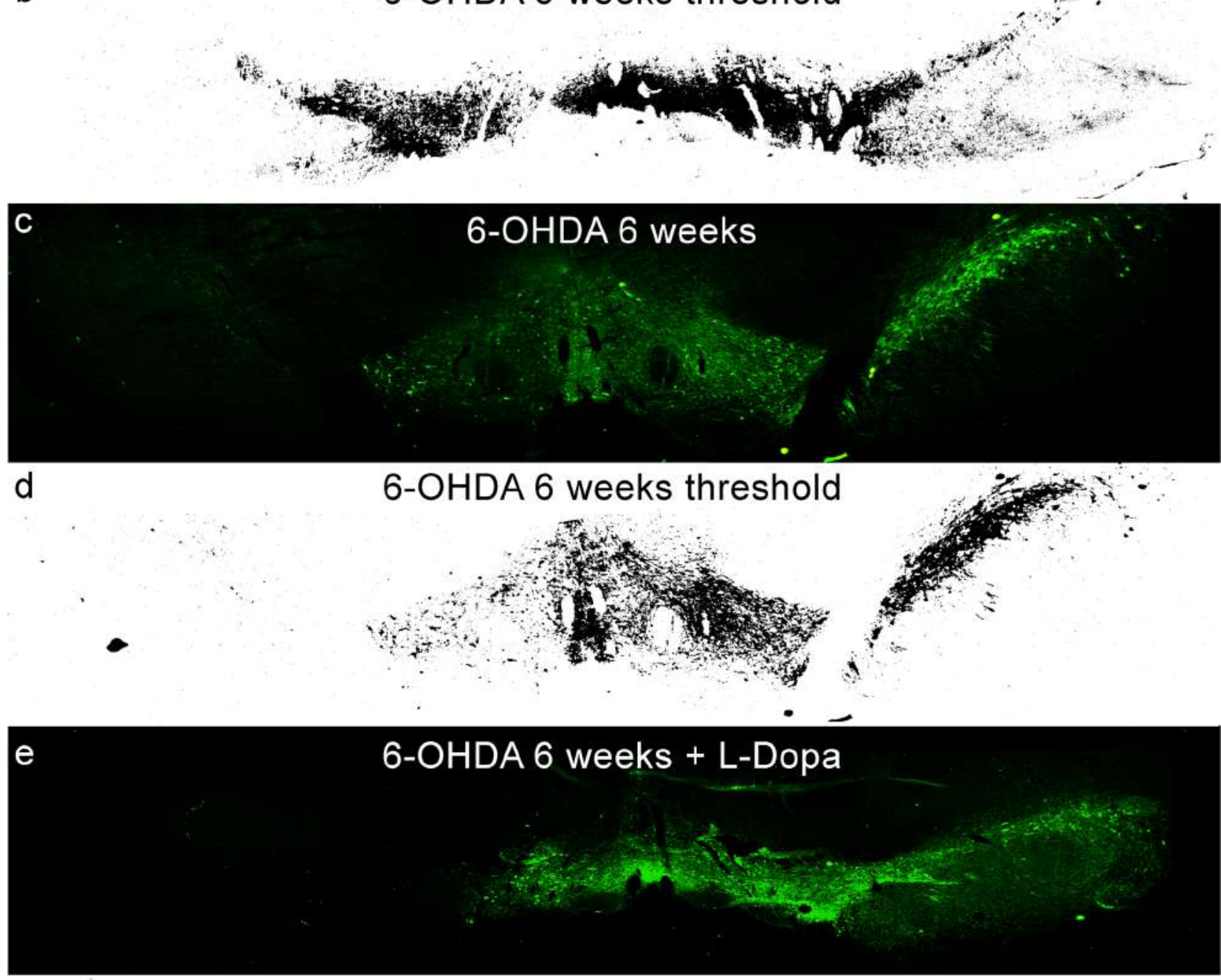

f

6-OHDA 6 weeks +L-Dopa threshold

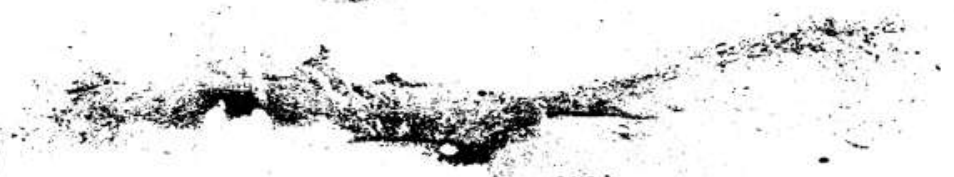

Fig. $4 \mathrm{TH}$ staining in substantia nigra of 6OHDA-lesioned rats. Representative lesioned sides in which $\mathrm{TH}$ immunostaining (Cy2, green labeling) is decreased at 3 weeks (a) and almost completely disappeared at 6 weeks (c), compared with unlesioned sides. L-Dopa treatment does not improve neurodegeneration (e). For each image, the background fluorescent signal was removed by a manual thresholding process (ImageJ) and the corresponding figures are shown $(\mathbf{b}, \mathbf{d}, \mathbf{f})$. TH, tyrosine hydroxylase. Scale bar $50 \mu \mathrm{m}$ 


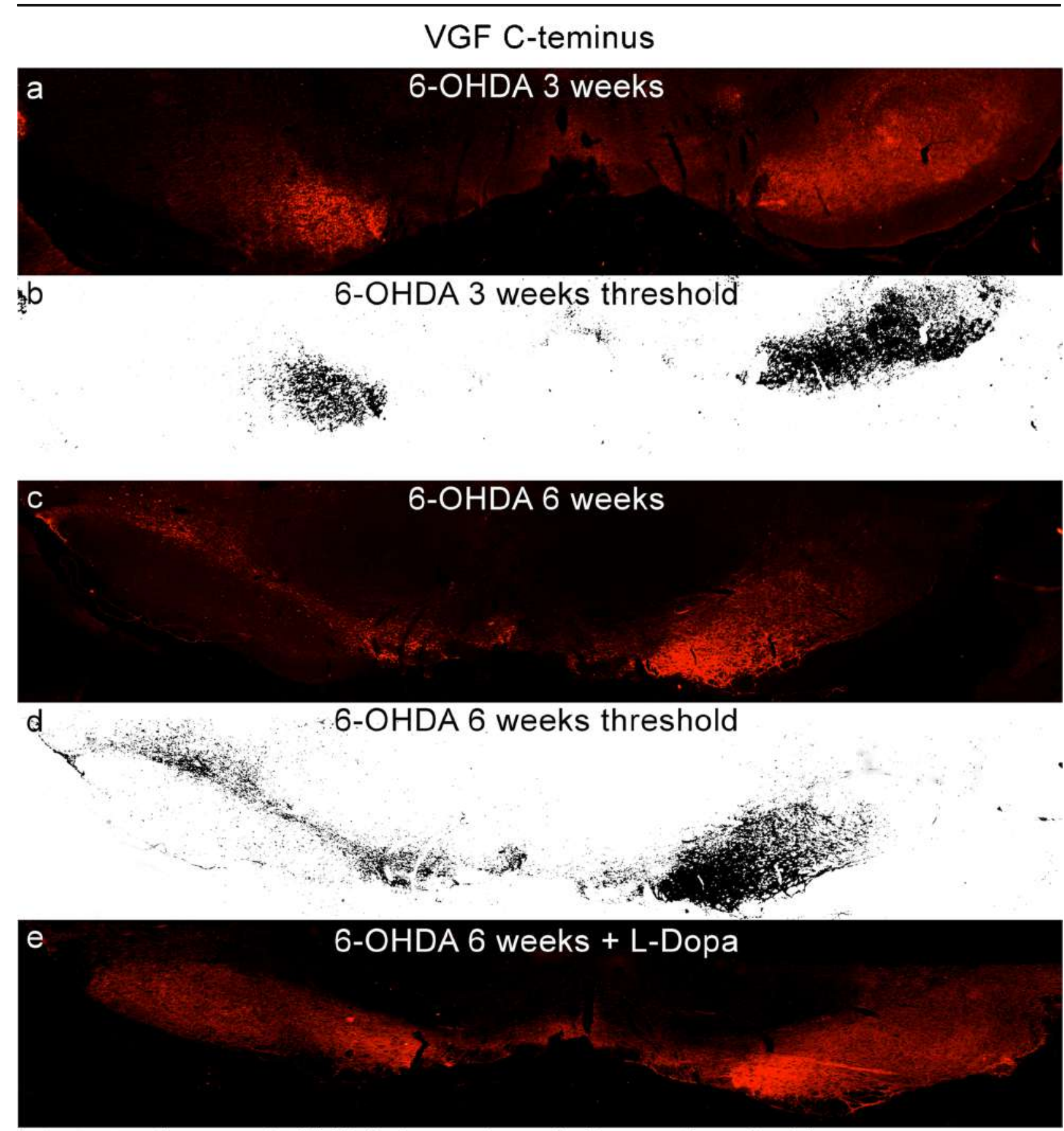

f

6-OHDA 6 weeks + L-Dopa threshold

6.
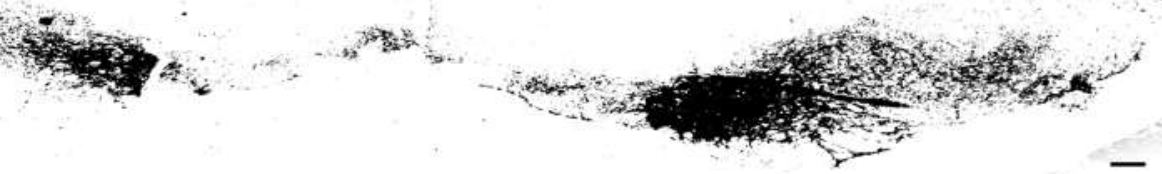

formic acid. The applied gradient was linear from 0 to $55 \%$ of solvent $\mathrm{B}$ in $35 \mathrm{~min}$, at a flow rate of $300 \mathrm{~nL} / \mathrm{min}$. The Elite-
Orbitrap mass spectrometer operated in a data-dependent mode in which each full MS scan (60,000 resolving power) 
4 Fig. 5 VGF C-t staining in substantia nigra of 6OHDA-lesioned rats. Representative lesioned sides in which VGF C-t immunostaining (Cy3 red labeling) is decreased at 3 weeks (a) but almost completely disappeared at 6 weeks (c), compared with unlesioned sides and restored after L-Dopa (e). For each image, the background fluorescent signal was removed by a manual thresholding process (ImageJ) and the corresponding figures are shown $(\mathbf{b}, \mathbf{d}, \mathbf{f})$. Scale bar $50 \mu \mathrm{m}$

was followed by five MS/MS scans where the first five multiple-charged ions were dynamically selected and fragmented by collision-induced dissociation (CID) at a normalized collision energy of $35 \%$. Peptide sequences and sites of covalent modifications were validated by manual spectra annotation performed by comparing experimental MS/MS spectra with the theoretical generated by the MS-Product program available on the Protein Prospector website (http://us. expasy.org/tools). The match was considered positive when all the experimental $\mathrm{m} / \mathrm{z}$ values with a relative abundance higher than $5 \%$ were present in the theoretical fragmentation spectrum and when differences between the experimental and theoretical values were less than $\pm 0.03 \mathrm{~m} / \mathrm{z}$.

\section{Statistical analyses}

Statistical analyses were carried out using StatistiXL software. For each experimental set, the normality of data distributions was preliminary checked using the goodness-of-fit test. Resulting $p$ values were $>0.05$ in all cases; hence, the following parametric tests were applied. Sample variances were measured with the $F$ test for equality of variance; hence, individual or pooled variances were used for two-tailed Student's $t$ test. Linear regression analysis was used to estimate possible correlations between plasma levels of VGF C-t peptides vs. years of disease, HY score scale, LEDD and olfactory dysfunction. In all cases, $p$ values $<0.05$ were deemed significant. No data points were excluded.

\section{Results}

\section{VGF C-t peptides in normal rats}

We analyzed the $\mathrm{SN}$ of the intact rats using antibodies against VGF C-t, TH, substance P and GAD (Fig. 2a-n). VGF labeling was found in neuron terminals of the entire $\mathrm{SN}$ and in close connection with $\mathrm{TH}$ containing perikarya but never inside them (Fig. 2a-f). The immunostaining profile of the VGF C-t antibody was similar to that obtained using substance $\mathrm{P}$ and GAD antibodies according to the high percentage of coexpression (Fig. $2 \mathrm{~g}-\mathrm{n}$ ). With the aim to have an indicative idea of the VGF C-t peptide concentration in the normal rats, we analyzed by ELISA the levels of these peptides in the frontal cortex, SN and caudate nucleus (Table 2). RP-HPLC highresolution-ESI-MS and MS/MS analyses performed in brain extracts of normal rat allowed identifying the $\mathrm{VGF}_{601-617}$ fragment encompassing the nonapeptide used for antibody immunization (Fig. 3).

\section{VGF C-t peptides in lesioned rats}

We analyzed possible immunoreactivity differences between the lesioned and unlesioned side using TH (Fig. 4), VGF (Fig. 5) and substance P (Fig. 6). As expected, dopaminergic neurons, revealed by the TH antibody (Fig. 4), were reduced 3 weeks after 6OHDA injection and were almost completely undetectable at 6 weeks in 3/7 lesioned rats (the remaining rats showed a high decrease without disappearing) and also after 1 week of L-Dopa treatment. Instead, VGF C-t immunostaining (Fig. 5) was decreased in short-term treated rats but it almost completely disappeared in the absence of dopaminergic neurons at 6 weeks (in the same 3/7 lesioned rats with absence of TH staining). L-Dopa administration markedly increased the VGF C-t immunoreactivity on the lesioned side. When we used substance P antibody (Fig. 6), an immunostaining reduction was observed at both 3 and 6 weeks postlesion. However, substance P staining was restored by 1 week of L-Dopa treatment. GAD immunostaining was also investigated through the animal groups but was unaffected by the lesion (not shown). By analyzing data obtained with ImageJ analysis (Fig. 7), statistically significant differences were revealed with TH-, VGF C-t- and SP-staining in lesioned vs. unlesioned sides. The differences remained statistically significant also after L-Dopa treatment despite a visible tendency to an immunoreactivity increase of VGF C-t and substance P in the lesioned side.

\section{VGF C-t peptides in human plasma}

We analyzed the VGF C-t peptide levels in the control subjects and PD patients either naïve or under pharmacological treatment (Fig. 8). VGF C-t peptide levels found in the control subjects were about $1504 \pm 587 \mathrm{pmol} / \mathrm{mL}$ (mean \pm S.E.M) while a severe reduction $(>50 \%)$ was revealed in drug-naïve patients at the time of the diagnosis ( $p<0.001$ vs. controls). While the decline of the VGF levels persisted also under short-term dopamine replacement therapy ( $p<0.001$ vs. controls), the long-term treatment instead was able to produce a VGF C-t increase compared with both naïve $(p<0.001)$ and short-term treated patients $(p<0.05)$. The characterization of the MW forms (Brancia et al. 2016; D'Amato et al. 2015) containing the VGF C terminus portion in plasma are summarized in panel $b$ of Fig. 8. We also correlated the plasma VGF levels with disease duration, LEDD and HY scores as well as with the severity of olfactory impairment (Fig. 8c-f). At the time of blood sampling, we observed a statistically significant positive linear relationship between VGF levels 

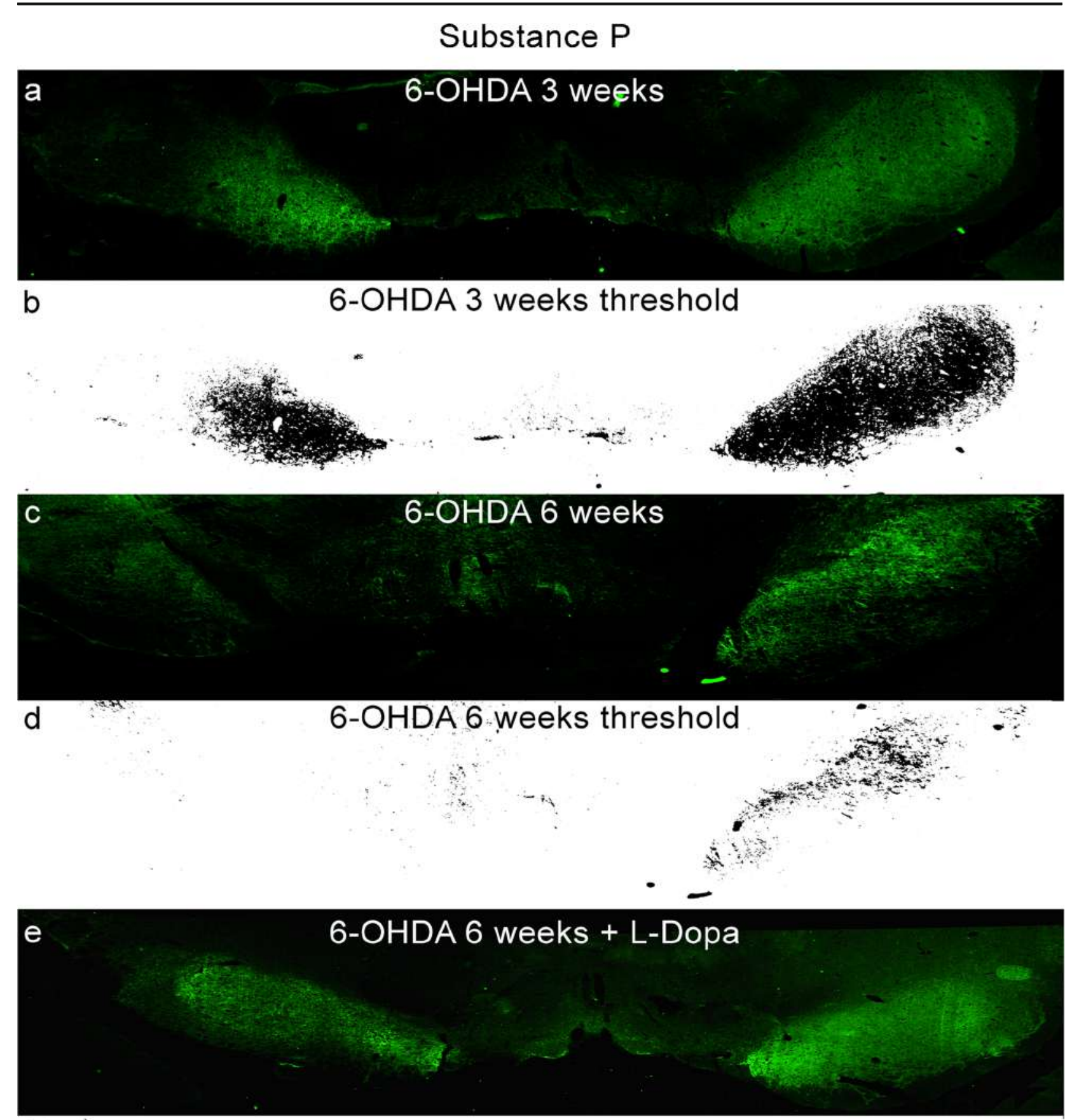

f

6-OHDA 6 weeks +L-Dopa threshold
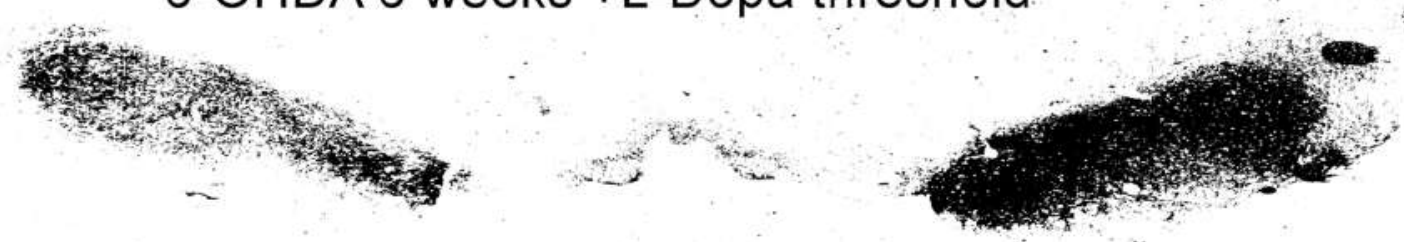

Fig. 6 Substance P staining in the Substantia nigra of the 6OHDAlesioned rats. Representative lesioned sides in which substance P immunostaining (Cy2 green labeling) is similarly decreased at 3 (a) and 6 weeks (c), compared with unlesioned sides and restored by L-Dopa

treatment (e). For each image, the background fluorescent signal was removed by a manual thresholding process (ImageJ) and the corresponding figures are shown $(\mathbf{b}, \mathbf{d}, \mathbf{f})$. Scale bar $50 \mu \mathrm{m}$ 
and both PD duration (Fig. 8c, $p<0.05$ ) and LEDD values (Fig. $8 \mathrm{~d}, p<0.05$ ) but no significant correlation was found with the HY scores (Fig. 8e, $p>0.05$ ). Furthermore, as confirmatory data, LEDD values were positively correlated with the years of disease (data not shown, $p<0.05$ ). In addition, in the short-term treated patients that underwent the olfactory test, a statistically significant negative linear relationship was found between VGF C-t levels and TDI scores (Fig. 8f). In particular, a significant correlation was observed between VGF C-t levels and odor discrimination but not with odor threshold and identification (Fig. 9a-c). Unfortunately, there were inadequate numbers of patients with cognitive impairment and dyskinesia to analyse these individual subgroups.

\section{Discussion}

Taken together, our results suggest that plasma VGF C-t peptide levels may be closely related to the brain dopamine content. Indeed, in the SN of the 6OHDA rat model, the VGF C-t peptide expression decreased according to the degree of dopaminergic neuron degeneration but it was restored by L-Dopa administration. Accordingly, in drug-naïve PD patients, the levels of the same peptide/s were decreased, while returning to normal values upon dopamine replacement therapy. In addition to immunochemical analyses, HPLC-ESI-MS unambiguously identified a 17 amino acid VGF C-t peptide, encompassing the very Cterminal stretch for which our antibodies are highly specific. In the $\mathrm{SN}$, neuron terminals containing both GAD and substance $\mathrm{P}$ are known to largely project from the striatum (Bolam and Smith 1990); hence, we hypothesize a similar origin for at least part of the VGF C-t peptide containing neuron terminals, in keeping with the reported high expression of VGF mRNA in a large number of striatal neurons (Snyder and Salton 1998). Since the VGF C-t peptide staining in the SN disappeared upon 6OHDA but re-appeared upon dopamine replacement treatment, its expression in the striatum appears to be under the control of the dopamine receptors. Indeed, L-Dopa may be converted to dopamine by a few surviving dopaminergic neurons in short-term lesioned rats and/or by serotoninergic axons in longterm treated rats (Carta et al. 2007). The resulting dopamine would restore the expression of the VGF C-t peptides in the striatum, hence their transport and release in the SN. Interestingly, dopamine release in the striatum in the MPTP model of PD is increased by the nerve growth factor (NGF; Garcia et al. 1992) that in turn induces VGF expression (Ferri et al. 2011). Hence, VGF itself might be involved in the overall dopaminergic regulation. The substance $\mathrm{P}$ is also decreased in the $\mathrm{SN}$, according to previous studies carried out in 6OHDAlesioned rats (Lindefors et al. 1989) in which the L-Dopa completely inverted the reduction (Engber et al. 1991). However, when substance P levels were investigated in PD patients, the outcomes were controversial due to the variability in plasma measures (Campbell et al. 2006). As mentioned, VGF $\mathrm{C}$-t fragments are abundant in human plasma and present so far in two forms: one may be compatible with the VGF precursor, while the other encompasses a small sequence recognized by HPLC-ESI-MS (Brancia et al. 2016; D'Amato et al. 2015). In agreement to the rat outcomes, the VGF C-t expression is downregulated in $\mathrm{PD}$ patients at the time of diagnosis with an increase during the course of the disease, probably induced by dopamine receptor activation during several years of dopamine replacement therapy. Indeed, a significant positive linear relationship is found between VGF levels and both the years of disease and LEDD but no significant correlation was observed with the severity of disease. This finding is not surprising because HY scores may be modified by the individual response to L-Dopa or

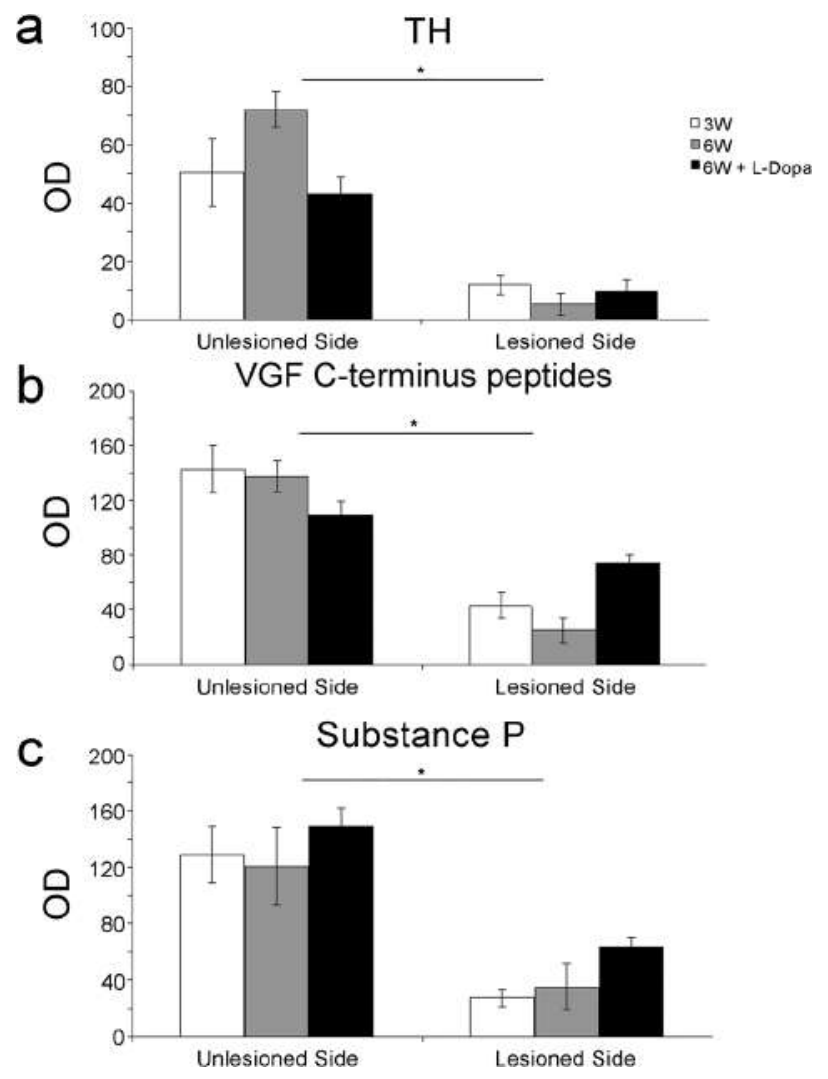

Fig. 7 OD measures in lesioned and unlesioned sides. Statistically significant differences of the optical density values are shown for $\mathrm{TH}$ in unlesioned $(50 \pm 11,71 \pm 5,42 \pm 6$; at 3, 6 weeks and after L-Dopa, respectively; means \pm SEM) vs. lesioned side $(11.8 \pm 3,5.3 \pm 3.6,9.3 \pm$ 3.9; at 3, 6 weeks, and after L-Dopa, respectively; means \pm SEM); VGF C-term in unlesioned $(142 \pm 17,137 \pm 11,109 \pm 10$; at 3, 6 weeks and after L-Dopa, respectively; means \pm SEM) vs. lesioned side ( $43 \pm 9,22 \pm$ $9,73.5 \pm 6$; at 3, 6 weeks and after L-Dopa, respectively; means \pm SEM) and substance $\mathrm{P}$ in unlesioned $(128 \pm 57,120 \pm 27,148 \pm 13$; at 3,6 weeks and after L-Dopa, respectively; means \pm SEM) vs. lesioned sides $(27 \pm 6,35 \pm 16,63 \pm 6$; at 3, 6 weeks and after L-Dopa, respectively; means \pm SEM). All $p<0.05$. OD, optical density 
a

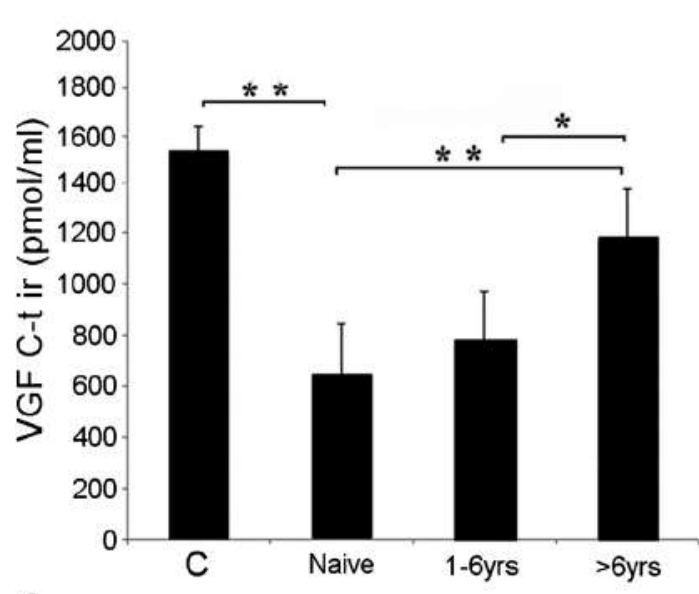

C

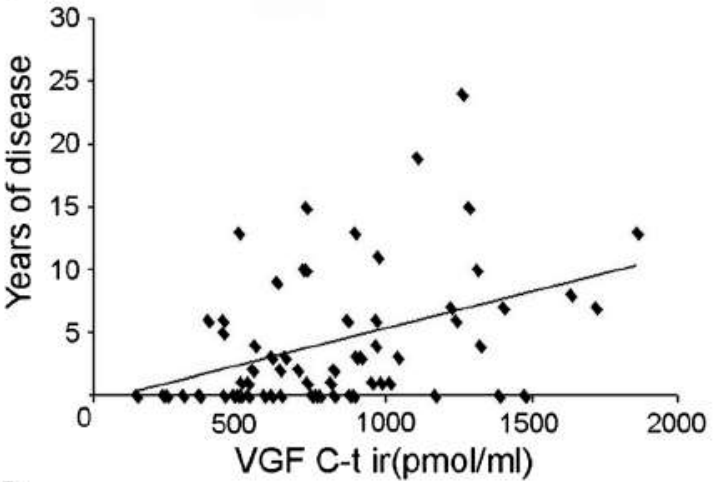

e

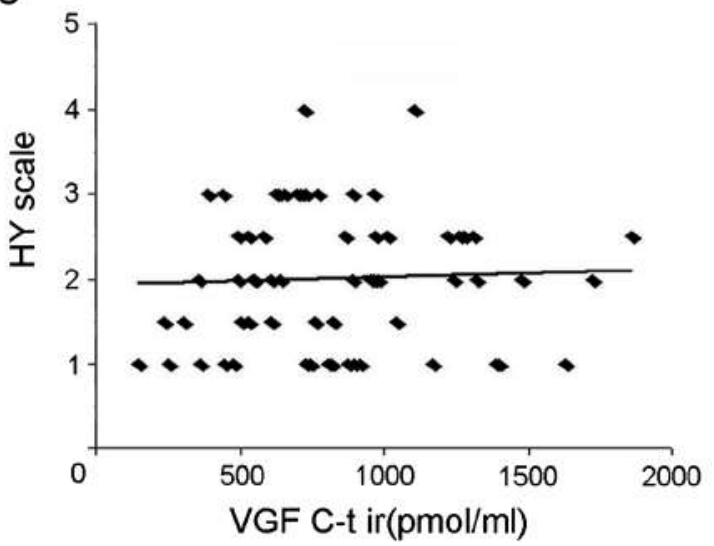

Fig. 8 VGF C-t in human plasma. Panel a. The VGF C-t levels (VGF C-t ir) were $1504 \pm 587 \mathrm{pmol} / \mathrm{mL}$ (means \pm S.E.M) in controls $(\mathrm{C}, n=21$ ); with a significant decrease in drug-naïve patients $(n=23 ; 643 \pm 348$ means \pm S.E.M, C vs. drug naïve: $p=0.0001$; DF: 32.0 ) and in the short-term treated group $(n=24 ; 1-6$ years; $766 \pm 257$, means \pm S.E.M; C vs. short-term treated group: $p=0.0001$; DF: 37.0). Instead, an increase was seen in long-term treated patients ( $>6$ years; $n=16 ; 1169$ \pm 414 ; mean \pm S.E.M) compared with the other two groups of patients. $* * p<0.001 ; * p<0.05$. Panel b. In normal human plasma, VGF C-t fragments are present in two forms recognized with gel chromatography coupled to ELISA: one $(66 \mathrm{kDa})$ is compatible with the VGF precursor, b
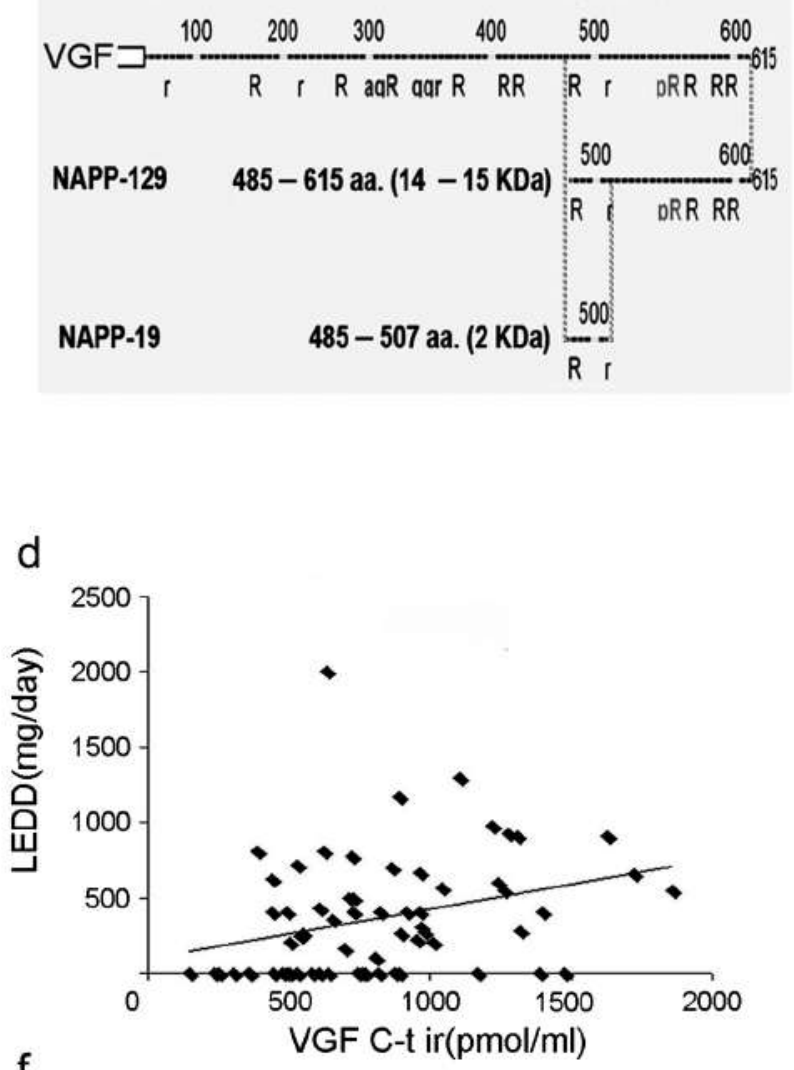

f

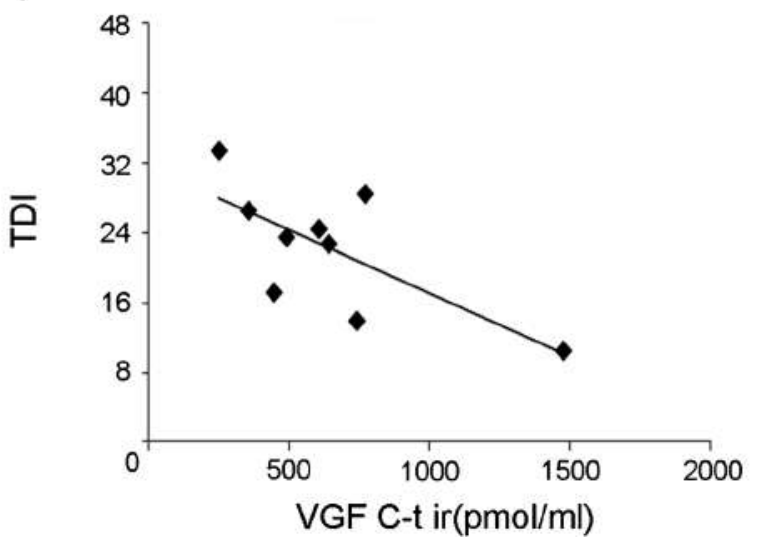

while the other, of 14-15 kDa and namely NAPP-129, encompasses a peptide (NAPP-19, of $2 \mathrm{kDa}$ ) recognized by HPLC-ESI-MS. c-f A statistically significant positive linear correlation is revealed between the VGF levels and both the years of disease (c, $* p<0.05, R=0.3)$ and the levodopa equivalent dose (LEDD), $(\mathbf{d} * p<0.05, R=0.3)$ but not with the Hoehn and Yahr (HY) scale scores $(\mathbf{e}, * p>0.05, R=0.2)$. A statistically significant negative linear correlation instead is seen between the VGF levels and TDI scores (the sum of odor threshold, discrimination and identification; $p<0.05, R=-0.7$ ). VGF $\mathrm{C}$ terminus immunoreactivity (VGF C-t ir) values are expressed as pmoles/milliliter 
other pharmacological treatment. As mentioned, since half of the normal VGF levels were found in the drug-naïve patients at the time of diagnosis, we hypothesize that the reduction may anticipate the current PD diagnosis. Plasmatic VGF C-terminal peptides may originate from the CSF that is in direct contact with the brain extracellular space and mirrors brain biochemical alterations. The identification of the VGF C-t peptide levels and sequences in the human brain (SN and striatum) and CSF could clarify and ensure the changes that we revealed in patient's plasma. However, at least part of the VGF content in the blood could originate from peripheral organs in which these peptides are produced (at least in the animal models) such as pituitary (Noli et al. 2014), adrenal medulla (D'Amato et al. 2008) and different gastric (Brancia C, 2010) and pancreatic endocrine cells (Cocco et al. 2007). VGF C-t peptides are also represented in sensory and sympathetic neurons of the enteric nervous system (Ferri et al. 2011; Possenti et al. 2012). The latter location may be of interest, in view of the proposed suggestions that PD could arise in the gut (Liddle 2018; Chapelet et al. 2019) and that the gut microbiota may exert a relevant role in disease development (Sampson et al. 2016). On such basis, a characterization of gastro-enteric VGF-expressing neurons and their changes in locally induced model/s of PD would be warranted. However, the unilaterally lesioned 6OHDA model of PD does not represent the best model to start investigating changes in the blood, due to the fact that the unlesioned side would likely compensate for the lack of release of the VGF C-t peptides from the lesioned side, resulting in controversial outcomes. Further experiments will be carried out with more appropriate models in order to better investigate this issue. As known, no specific test exists for PD diagnosis particularly at disease onset and the patients with uncertain diagnosis may wait a long time before receiving it precisely. To note, short-term treated patients showed a significant negative linear relationship between VGF C-t levels and olfactory dysfunction, an early sign of PD. The negative relationship with the TDI scores is probably due to the worsening of the olfactory performance during the $\mathrm{PD}$ progression in contrast to the increasing levels of VGF C-t peptides after the start of the dopamine replacement therapy. In particular, a significant correlation was observed between VGF C-t peptide levels and odor discrimination. Indeed, odor threshold is more related to the peripheral olfactory epithelium and associated with the inter-individual differences of the nasal cavity volume (Masala et al. 2019). Odor discrimination and identification both involve cognitive processes such as the orbitofrontal cortex (Duuren et al. 2007). The lack of significant correlation between VGF C-t peptide levels and odor identification could be due to the low number of patients involved in the test. Since olfactory dysfunction is an early sign of PD, future longitudinal studies will be carried out involving subjects at the first neurological examination (suspected of having PD) to evaluate how many patients having olfactory alteration combined with VGF reduction will later receive a PD diagnosis, strengthening the use of VGF C-t peptides as early PD biomarkers. Unfortunately, there are no data available as yet on the other neurodegenerative diseases, apart from ALS, in which the VGF C-t peptides are marginally decreased in a late stage only (Brancia et al. 2016), while other VGF-derived peptides namely TLQP peptides are decreased early (Brancia et al. 2018). Future studies are
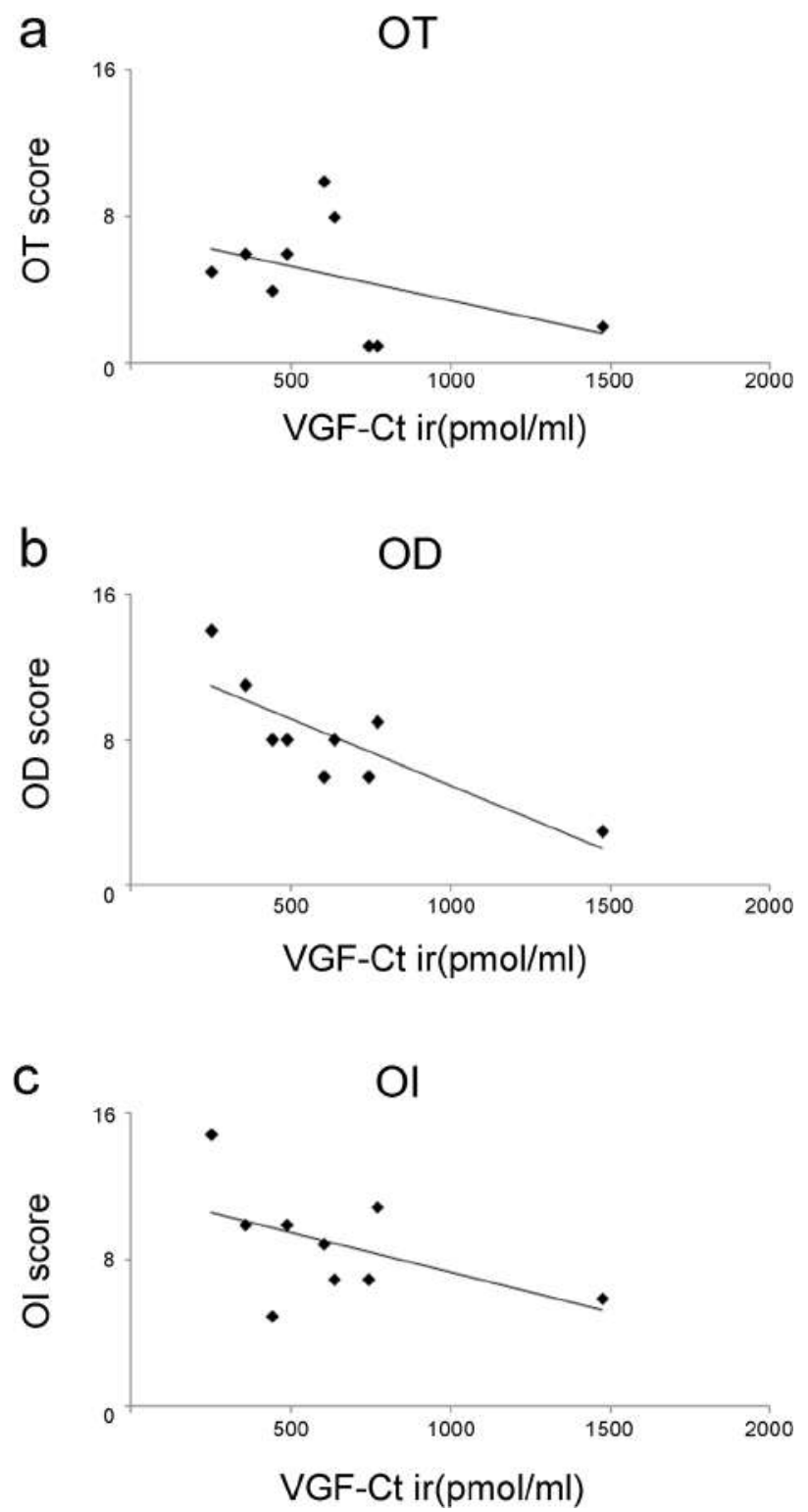

Fig. 9 VGF C-t levels and olfactory dysfunction. Correlations between VGF levels and odor threshold (a) $(p>0.05, R=-0.43)$, discrimination (b) $(p<0.01, R=-0.82)$ and identification (c) $(p>0.05, R=-0.51)$. A statistically significant negative linear correlation is found with odor discrimination only. VGF C terminus immunoreactivity (VGF C-t ir) values are expressed as pmoles/milliliter 
also needed to identify if VGF C-t peptide changes are peculiar to $\mathrm{PD}$, by analyzing other neurodegenerative diseases. It is interesting to note that in schizophrenia untreated patients with first onset, VGF N-terminal fragments are increased in the CSF (Busse et al. 2012) while VGF C-terminal peptides increased in the prefrontal cortex of phencyclidine-treated rats (Noli et al. 2017). Since schizophrenia profiles are often characterized by increased dopamine transmission within the striatum (Howes et al. 2015), this observation may corroborate the idea that VGF expression is under the control of striatal dopamine receptors.

\section{Conclusions}

The main finding of this study is the correlation between plasma VGF C-t peptide levels and dopamine brain content, making these peptides suitable as early PD diagnostic biomarkers. Furthermore, such biomarkers may not only allow an earlier and more precise identification of patients with PD but would also be extremely important for neuroprotective trials, where recruitment of early stages $\mathrm{PD}$ patients may be a key factor for successful outcomes.

\begin{abstract}
Author contributions Cristina Cocco and Giulia Corda designed the study, provided immunohistochemistry experiments and wrote the manuscript; Carlo Lisci and Manolo Carta provided the animal model, designed the study and reviewed the manuscript; Carla Brancia and Elias Manca provided immunohistochemistry experiments; Barbara Noli provided ELISA experiments; Carla Masala provided the olfactory test and reviewed the manuscript; Francesco Marrosu, Paolo Solla, and Paolo Bongioanni provided patients, designed the study, and reviewed the manuscript; Barbara Manconi provided the spectrometry analysis and reviewed the manuscript; Gian-Luca Ferri designed the study and reviewed the manuscript.
\end{abstract}

Funding information This work was supported by the NeuroCare Onlus and Interdisciplinary Human Movement and Rehab Research Laboratory (HuMoRe) (no-profit associations). No other funding was available.

\section{Compliance with ethical statements}

Conflict of interest The authors declare that they have no conflict of interest.

Informed consent Informed consent was obtained from all individual participants included in the study.

Ethical approval All applicable international, national and/or institutional guidelines for the care and use of animals were followed, according to the regulations set by the European Union (EEC Council 86/609; D.P.R. 116/92) and approved by the Ethical Committee of the University of Cagliari in agreement with Italian legislation. All procedures performed in studies involving human participants were in accordance with the ethical standards of the institutional and/or national research committee and with the 1964 Helsinki Declaration and its later amendments or comparable ethical standards.

\section{References}

Alder JS, Thakker-Varia DA, Bangasser M, Kuroiwa MR, Plummer TJ, Shors IB, Black IB (2003) Brain-derived neurotrophic factorinduced gene expression reveals novel actions of VGF in hippocampal synaptic plasticity. J Neurosci 23(34):10800-10808

Bolam JP, Smith Y (1990) The GABA and substance P input to dopaminergic neurones in the substantia nigra of the rat. Brain Res 529:5778

Brancia C, Cocco C, D'Amato F, Noli B, Sanna F, Possenti R, Argiolas A, Ferri GL (2010) Selective expression of TLQP-21 and other VGF peptides in gastric neuroendocrine cells and modulation by feeding. J Endocrinol 207(3):329-341

Brancia C, Noli B, Boido M, Boi A, Puddu R, Borghero G, Marrosu F, Bongioanni P, Orrù S, Manconi B, D'Amato F, Messana I, Vincenzoni F, Vercelli A, Ferri GL, Cocco C (2016) VGF protein and its C-terminal derived peptides in amyotrophic lateral sclerosis: human and animal model studies. PLoS One. https://doi.org/10. 1371/journal.pone. 0164689

Brancia C, Noli B, Boido M, Pilleri R, Boi A, Puddu R, Marrosu F, Vercelli A, Bongioanni P, Ferri G-L, Cocco C (2018) TLQP peptides in amyotrophic lateral sclerosis: possible blood biomarkers with a neuroprotective role. Neuroscience 380:152-163

Busse S, Bernstein HG, Busse M, Bielau H, Brisch R, Mawrin C, Müller S, Sarnyai Z, Gos T, Bogerts B, Steiner J (2012) Reduced density of hypothalamic VGF-immunoreactive neurons in schizophrenia: a potential link to impaired growth factor signaling and energy homeostasis. Eur Arch Psychiatry Clin Neurosci 262(5):365-374

Campbell DE, Raftery N, Tustin R, Tustin NB, Desilvio ML, Cnaan A, Aye PP, Lackner AA, Douglas SD (2006) Measurement of plasmaderived substance P: biological, methodological, and statistical considerations. Clin Vaccine Immunol 13(11):1197-1203

Carta M, Carlsson T, Kirik D, Björklund A (2007) Dopamine released from 5-HT terminals is the cause of L-DOPA-induced dyskinesia in parkinsonian rats. Brain 130(7):1819-1833

Chapelet G, Boureau AS, Montassier E, Le Bastard Q, Batard E, Lepelletier D, Berrut G, De Decker L (2019) Cancer and microbiota in elderly patients: challenges and management. Geriatr. Psychol Neuropsychiatr Vieil 17(1):20-30

Cocco C, Brancia C, Pirisi I, D'amato D, Noli B, Possenti R, Ferri GL (2007) VGF metabolic-related gene: distribution of its derived peptides in mammalian pancreatic islets. J Histochem Cytochem 55(6): $619-628$

Cocco C, D'Amato F, Noli B, Ledda A, Brancia C, Bongioanni P, Ferri GL (2010) Distribution of VGF peptides in the human cortex and their selective changes in Parkinson's and Alzheimer's diseases. J Anat 217(6):683-693

D’Amato F, Noli B, Brancia C, Cocco C, Flore G, Collu M, Nicolussi P, Ferri GL (2008) Differential distribution of VGF-derived peptides in the adrenal medulla and evidence for their selective modulation. $\mathrm{J}$ Endocrinol 197(2):359-369

D’Amato F, Cocco C, Noli B, Cabras T, Messana I, Ferri GL (2012) VGF peptides upon osmotic stimuli: changes in neuroendocrine regulatory peptides 1 and 2 in the hypothalamic-pituitary-axis and plasma. $\mathrm{J}$ Chem Neuroanat 44(2):57-65

D'Amato F, Noli B, Angioni L, Cossu E, Incani M, Messana I, Manconi B, Solinas P, Isola R, Mariotti S, Ferri GL, Cocco C (2015) VGF peptide profiles in type 2 diabetic patients' plasma and in obese mice. PLoS One. https://doi.org/10.1371/journal.pone.0142333

Duuren EV, Escámez FA, Joosten RN, Visser R, Mulder AB, Pennartz CM (2007) Neural coding of reward magnitude in the orbitofrontal cortex of the rat during a five-odor olfactory discrimination task. Learn Mem 14(6):446-456

Engber TM, Susel Z, Kuo S, Gerfen CR, Chase TN (1991) Levodopa replacement therapy alters enzyme activities in striatum and 
neuropeptide content in striatal output regions of 6 hydroxydopamine lesioned rats. Brain Res 552(1):113-118

Ferri GL, Noli B, Brancia C, D'Amato F, Cocco C (2011) VGF: an inducible gene product, precursor of a diverse array of neuroendocrine peptides and tissue-specific disease biomarkers. J Chem Neuroanat 42(4):249-261

Garcia E, Rios C, Sotelo J (1992) Ventricular injection of nerve growth factor increases dopamine content in the striata of MPTP-treated mice. Neurochem Res 17(10):979-982

Hoehn MM, Yahr MD (1967) Parkinsonism: onset, progression, and mortality. Neurology 17(5):427-442

Howes O, McCutcheon R, Stone J (2015) Glutamate and dopamine in schizophrenia: an update for the 21 st century. J Psychopharmacol 29(2):97-115

Liddle RA (2018) Parkinson's disease from the gut. Brain Res 1693:201206

Lindefors N, Brodin E, Tossman U, Segovia J, Ungerstedt U (1989) Tissue levels and in vivo release of tachykinins and GABA in striatum and substantia nigra of rat brain after unilateral striatal dopamine denervation. Exp Brain Res 74 (3)527-5234

Masala C, Defazio G, Cannas A, Cavazzana A, Hummel T, Haehner A (2018) Correlation among olfactory function, motors' symptoms, cognitive impairment, apathy, and fatigue in patients with Parkinson's disease. J Neurol 265(8):1764-1771

Masala C, Käehling C, Fall F, Hummel T (2019) Correlation between olfactory function, trigeminal sensitivity, and nasal anatomy in healthy subjects. Eur Arch Otorhinolaryngol. https://doi.org/10. 1007/s00405-019-05367-y

Noli B, Brancia C, D’Amato F, Ferri GL, Cocco C (2014) VGF changes during the estrous cycle: a novel endocrine role for TLQP peptides? PLoS One. https://doi.org/10.1371/journal.pone.0108456

Noli B, Brancia C, Pilleri R, D'Amato F, Messana I, Manconi B, Ebling FJ, Ferri GL, Cocco C (2015) Photoperiod regulates vgf-derived peptide processing in Siberian hamsters. PLoS One. https://doi. org/10.1371/journal.pone.0141193

Noli B, Sanna F, Brancia C, D'Amato F, Manconi B, Vincenzoni F, Messana I, Melis MR, Argiolas A, Ferri GL, Cocco C (2017) Profiles of VGF peptides in the rat brain and their modulations after phencyclidine treatment. Front Cell Neurosci doi. https://doi.org/10. 3389/fncel.2017.00158

Possenti R, Muccioli G, Petrocchi P, Cero C, Cabassi A, Vulchanova L, Riedl MS, Manieri M, Frontini A, Giordano A, Cinti S, Govoni P, Graiani G, Quaini F, Ghè C, Bresciani E, Bulgarelli I, Torsello A, Locatelli V, Sanghez V, Larsen BD, Petersen JS, Palanza P, Parmigiani S, Moles A, Levi A, Bartolomucci A (2012) Characterization of a novel peripheral pro-lipolytic mechanism in mice: role of VGF-derived peptide TLQP-21. Biochem J 441(1): 511-522

Postuma RB, Gagnon JF, Bertrand JA, Genier Marchand D, Montplaisir JY (2015) Parkinson risk in idiopathic REM sleep behavior disorder preparing for neuroprotective trials. Neurology 84(11):1104-1113

Sampson TR, Debelius JW, Thron T, Janssen S, Shastri GG, Ilhan ZE, Challis C, Schretter CE, Rocha S, Gradinaru V, Chesselet MF, Keshavarzian A, Shannon KM, Krajmalnik-Brown R, WittungStafshede P, Knight R, Mazmanian SK (2016) Gut microbiota regulate motor deficits and neuroinflammation in a model of Parkinson's disease. Cell 167(6):1469-1480.e12

Smith AH, Corneveaux JJ, De Both M, Cuyugan L, Liang WS, Huentelman M, Adler C, Driver-Dunckley E, Beach TG, Dunckley TL (2016) Next-generation profiling to identify the molecular etiology of Parkinson dementia. Neurol Genet 2(3):e75

Snyder SE, Salton SR (1998) Expression of VGF mRNA in the adult rat central nervous system. J Comp Neurol 394(1):91-105

Trani E, Ciotti T, Rinaldi AM, Canu N, Ferri GL, Levi A, Possenti R (1995) Tissue-specific processing of the neuroendocrine protein VGF. J Neurochem 65(6):2441-2449

Trani E, Giorgi A, Canu N, Amadoro G, Rinaldi AM, Halban PA, Ferri GL, Possenti RSME, Levi A (2002) Isolation and characterization of VGF peptides in rat brain. Role of PC1/3 and PC2 in the maturation of VGF precursor. J Neurochem 81(3):565-574

Van Den Pol AN, Keshavan B, Decavel C, Prabhat G (1994) VGF expression in the brain. J Comp Neurol 347:455-469

Publisher's note Springer Nature remains neutral with regard to jurisdictional claims in published maps and institutional affiliations. 